

\title{
FERRAMENTAS DA QUALIDADE APLICADAS NA PRODUÇÃO DE SOFTWARE: UM ESTUDO BIBLIOMÉTRICO
}

\author{
QUALITY TOOLS APPLIED IN SOFTWARE PRODUCTION: A BIBLIOMETRIC STUDY
}

\author{
iD Helton Messias Adigneri ${ }^{1}$ \\ iD Edwin Vladimir Cardoza Galdamez ${ }^{2}$ \\ iD Danilo Hisano Barbosa ${ }^{3}$ \\ D Juliana Sayuri Kurumoto ${ }^{4}$
}

1

Graduando em Engenharia de Produção Universidade Estadual de Maringá - UEM. Maringá, PR - Brasil.

adigneri@hotmail.com

2 Doutor em Engenharia de Produção

Universidade Estadual de Maringá - UEM. Maringá, PR - Brasil.

evcgaldamez@uem.br

3 Doutor em Engenharia de Produção Universidade Estadual de Maringá - UEM. Maringá, PR - Brasil.

dhbarbosa@uem.br

4 Doutora em Engenharia de Produção Universidade Estadual de Maringá - UEM. Maringá, PR - Brasil.

sayuri.juliana@gmail.com

Recebido em: 17 jul. 2020

Aprovado em: 09 out. 2020
Resumo: O objetivo deste trabalho é identificar a partir de uma análise bibliométrica as ferramentas da qualidade mais utilizadas nos processos de avaliação da qualidade na indústria de software. Para isso foi analisada a distribuição da produção científica no período de 1998 a 2018. Métodos bibliométricos de co-authorship e co-occurrence foram implementados pelo software VOSviewer utilizando uma base de dados com 862 publicações de um total de 3.560 publicações da base Techonology Collection da plataforma ProQuest. Os resultados mostram as ferramentas da qualidade mais recorrentes para avaliação da qualidade de software, os autores que mais pesquisam sobre o tema a partir da frequência de citação, mapeou-se as redes de co-autoria e coocorrência de terminologias. A pesquisa revela uma possível tendência de ferramentas para o controle de qualidade na indústria de software e auxilia na investigação com empresas para verificar as ferramentas utilizadas e sua finalidade de uso, possibilitando encontrar novas lacunas de pesquisa.

Palavras-chave: Ferramentas da qualidade. Engenharia da qualidade. Qualidade de software.

Abstract: The aim of this study is to identify the quality tools most used in the quality assessment processes in the software industry from a bibliometric analysis. For this, the distribution of scientific production in the period from 1998 to 2018 was analyzed. Bibliometric methods of co-authorship and co-occurrence were implemented by the VOSviewer software using a database with 862 publications out of a total of 3,560 publications from the Techonology Collection database of ProQuest platform. The results show the most recurring quality tools in software quality, the authors who research the most on the subject from the frequency of citation, mapped the networks of coauthorship and co-occurrence of terminologies. The research reveals a possible trend of tools for quality control in the software industry and assists in the investigation with companies to verify the tools used and their purpose of use, making it possible to find new research gaps.

Keywords: Quality tools. Quality engineering. Quality software. 
1 Introdução

A partir dos anos 90, o Brasil começou a vivenciar uma abertura de mercado significativa, fazendo com que a indústria nacional se preocupasse com a qualidade de seus produtos e serviços, tanto para serem competitivas no mercado nacional ou para se consolidarem como exportadores. Conceitos de qualidade total se tornaram comum nos setores industriais e de serviços, com o objetivo principal de alcançarem uma fatia de mercado significativa e ao mesmo tempo garantindo lucro a partir de seus processos produtivos. Esse fato se comprova pelo aumento do número de certificações ISO 9001 (Mello, 2012; da Silva \& Barbosa, 2017).

Segundo Pressman (2011), também foi na década de 90 que se deu início a um importante apelo por qualidade de software, quando as empresas perceberam que estavam perdendo bilhões de dólares, pois os softwares não estavam apresentando as funcionalidades desejadas. Softwares sem qualidade causavam desperdícios de dinheiro com manutenções e com perdas da produtividade, principalmente com erros de codificação. Problemas com qualidade de software persiste até os dias atuais. Como indicado pelo relatório Chaos (2015), 29\% dos projetos tiveram êxito, ou seja, concluídos no prazo, dentro do orçamento e com uma qualidade satisfatória, mostrando que ainda precisa evoluir a qualidade em projetos de desenvolvimento de software. Quando se refere a qualidade de software, duas classificações surgem: qualidade do produto e do processo de produção ou desenvolvimento (Velthuis et al., 2010).

A gestão da qualidade total tornou-se difundida no meio industrial. Houve um desejo de conhecimento acerca das ferramentas da qualidade que proporcionaram ao Japão um rápido e sólido crescimento industrial. A gestão da qualidade total foi incorporada ao longo do tempo e da evolução do conceito de qualidade no âmbito organizacional (Mello, 2012). Para Carvalho e Paladini (2012), as ferramentas da gestão da qualidade garantem a aplicação prática dos seus princípios e definições, deste modo desempenham um papel importante no desenvolvimento da gestão da qualidade.

Para Sommerville (2011), a Engenharia de Software iniciou o desenvolvimento de técnicas formais de gerenciamento da qualidade de software partindo-se de métodos utilizados pelas indústrias de manufatura. Entretanto, o estudo realizado por Ghanbari et al. (2018) demonstra que na indústria de software existe um desconhecimento sobre as práticas de qualidade que apoiam o processo de tomada de decisão e contribuem para gerenciar as estratégias. É um ambiente industrial que demanda o desenvolvimento de habilidades gerenciais e de liderança da equipe de desenvolvedores para alcançar sucesso na implantação de um processo de melhoria do software (Almomani et al., 2018).

Com esses dois cenários, o da necessidade de qualidade de software e da utilização das ferramentas da qualidade, surge a oportunidade de investigar como a indústria de software utiliza as ferramentas propostas pela Engenharia da Qualidade. 
A Associação Brasileira das Empresas de Software (ABES, 2019) destaca que o Brasil ocupou em 2018 a 9ạ posição mundial em investimentos no setor de tecnologia da informação, sendo o primeiro colocado quando o mercado é a américa latina, desenvolvendo atividades de criação de softwares, hardwares e prestação de serviços em T.I. (Tecnologia da Informação).

O termo indústria de software refere-se a empresas de desenvolvimento de softwares, que possuem para tal, um processo de desenvolvimento estruturado, controlado e de forma contínua, com atendimento a múltiplas demandas de natureza e escopo diferentes, com objetivo de criar o produto software em conformidade com a documentação de requisitos e de forma produtiva e economicamente viável (Fernandes \& Teixeira, 2004).

Desta forma, para garantir o recebimento de novos investimentos que consolide o país como referência de desenvolvimento de software com qualidade é necessário que as empresas tenham uma gestão da qualidade consolidada, utilizando ferramentas que apoiam o desenvolvimento de produtos e processos com garantias mínimas de qualidade, afim de que se tenham produtos competitivos a um custo menor, o que torna essencial saber quais ferramentas da qualidade as empresas estão utilizando ao fazerem sua gestão em qualidade, desde modo, entregando ao cliente um produto que além de implementar valor, seja de qualidade satisfatória.

Assim, há uma oportunidade de identificar quais das ferramentas da qualidade são utilizadas pela indústria de software, e quais os objetivos esperados com tal utilização por essas indústrias. Ainda, a pesquisa determina a intersecção do uso das ferramentas da gestão da qualidade, próprias da engenharia de produção, com os processos de engenharia de software.

O objetivo principal deste trabalho, portanto, é identificar quais das ferramentas da qualidade são utilizados na Engenharia de Software para que consiga garantir qualidade, seja no processo ou no produto.

A delimitação deste estudo reside na aplicação da análise bibliométrica com a finalidade de classificar as ferramentas da gestão da qualidade em ordem crescente de utilização em processos de garantia de qualidade de software, tendo como fonte de dados publicações de artigos científicos.

\section{Revisão da literatura}

\subsection{Ferramentas de controle da qualidade}

Para Benabdellah et al. (2020), o conceito de qualidade é um tema que sempre é abordado por vários pesquisadores porque a qualidade pode ser vista de várias formas e a partir de diferentes dimensões de desempenho ou atributos. Para Miguel (2001), não existe um termo único que define o que é qualidade, mas sim um conjunto de atributos, propriedades ou características que são relacionados a um produto tangível ou intangível. 
Em diferentes pesquisas observa-se que a qualidade pode ser definida pelos tipos de abordagens que as indústrias utilizam para a apoiar a estratégia de negócios. Neste caso, qualidade é uma abordagem transcendente; sabe-se o que é qualidade, mas não se consegue defini-la. Outro modo de definir qualidade é se referindo aos clientes ou usuários de um produto; ou seja, quais as percepções que os clientes têm sobre um produto ou serviço, pontos negativos e positivos. Outra abordagem é a definição pela conformidade da produção; os produtos têm que ter as especificações exigidas. A definição da qualidade referenciando-se ao produto ocorre quando se observa às diferenças na qualidade de alguns ingredientes ou atributos desejados. Por fim, a definição de qualidade pela perspectiva do valor diz que a qualidade é ter um produto a preço aceitável e possuir um controle da variabilidade a custo aceitável (Garvin, 2002; Pirsig, 1974; Juran \& Gryna 1991; Deming, 1990; Crosby, 1984; Abbott, 1955; Broh, 1982). As ferramentas da qualidade têm o papel fundamental na tradução da abordagem utilizada para os controles operacionais e para apoiar o gerenciamento da qualidade. Os gerentes ou tomadores de decisão utilizam estas ferramentas para detectar problemas, encontrar causas, planejar e desenvolver ações corretivas e preventivas e monitorar soluções, melhorando a comunicação e a compreensão do processo (Castello et al., 2020). Os problemas podem ser antecipados pelo uso das ferramentas da qualidade, que são simples e de fácil entendimento (Corrêa \& Corrêa, 2012).

Para Miguel (2001), nem todas as ferramentas da qualidade podem ser denominadas de ferramentas estatísticas da qualidade. Existem um outro grupo de ferramentas tradicionais da qualidade ou ferramentas de controle da qualidade, que são destinadas ao gerenciamento da qualidade.

Tarí e Sabater (2004) classificam as técnicas e ferramentas da qualidade, a partir das ferramentas da gestão da qualidade, dividindo-as em quatro grupos: ferramentas básicas da qualidade, ferramentas da gestão da qualidade, outras ferramentas e técnicas utilizadas na qualidade, conforme o Quadro 1. 


\section{Quadro 1}

Classificação dos principais métodos e ferramentas da qualidade

\begin{tabular}{|c|c|c|c|}
\hline $\begin{array}{l}\text { Ferramentas básicas } \\
\text { da qualidade }\end{array}$ & $\begin{array}{l}\text { Ferramentas de gestão } \\
\text { da qualidade }\end{array}$ & Técnicas da qualidade & Outras ferramentas \\
\hline $\begin{array}{c}\text { Diagrama de Causa e } \\
\text { Efeito }\end{array}$ & Diagrama de Afinidades & Benchmarking & Brainstorming \\
\hline Folha de Verificação & Diagrama de Setas & $\begin{array}{l}\text { QFD -Desdobramento da } \\
\text { Função da Qualidade }\end{array}$ & Fluxograma \\
\hline Gráfico de Controle & Matriz de Priorização & DOE - Desing of Experiments & $\begin{array}{c}\text { ARA - Árvore da Realidade } \\
\text { Atual }\end{array}$ \\
\hline Estratificação & Matriz de Relações & $\begin{array}{c}\text { FMEA - Análise de Modo e } \\
\text { Efeito } \\
\text { de Falhas }\end{array}$ & $5 \mathrm{~W} 1 \mathrm{H}$ \\
\hline Histograma & $\begin{array}{c}\text { Diagrama de Processo } \\
\text { Decisório }\end{array}$ & Poka-Yoke & \\
\hline Diagrama de Pareto & Diagrama de Relações & $\begin{array}{l}\text { MASP - Método de Análise e } \\
\text { Solução de Problemas }\end{array}$ & \\
\hline \multirow[t]{2}{*}{$\begin{array}{l}\text { Diagrama de } \\
\text { Dispersão }\end{array}$} & Diagrama em Árvores & PDCA - Plan, Do, Check, Act & \\
\hline & & $\begin{array}{c}\text { CEP - Controle Estatístico do } \\
\text { Processo }\end{array}$ & \\
\hline
\end{tabular}

Fonte: Adaptado de Tarí e Sabater (2004).

$\mathrm{Na}$ literatura é possível encontrar estudos que relacionam um ou outra ferramenta da engenharia da qualidade a área de software. Como por exemplo, Bonanomi et al (2010), que utiliza FMEA para priorização de riscos em projetos de software; Já Sonda, Ribeiro e Echeveste (2000) e Scalvenzi e Miguel (2016) utilizaram a matriz QFD como forma de planejar o desenvolvimento do software de forma a atender os requisitos dos clientes. Middleton (2001) cita o Poka-Yoke como uma das ferramentas utilizadas em desenvolvimento de software para erradicar erros e localizar a causa raiz dos mesmos. Fonseca (2010), por sua vez, apresentou um modelo para controle estatístico de processo de desenvolvimento de software em pequenas e médias empresas e Silva e Milfont (2019) apresentam uma proposta de adaptação do MASP às etapas do Scrum. Por fim, Perucci e Campos (2016) apresentam técnicas de qualidade relacionadas a modelo de maturidade e normas de qualidade aplicadas a softwares como forma de controle de qualidade.

\subsection{Qualidade de software}

Pressman (2011), define qualidade, no contexto de software, dizendo que todos os sistemas computacionais construídos com qualidade deverão atender todos os requisitos funcionais e de desempenho e todas as regras de desenvolvimento que foram documentadas no início do projeto. Galin (2018) e Yue (2019) complementam ainda que a qualidade deve atender as necessidades dos stakeholders. Florac (1992) e Chauhan (2014) descrevem duas métricas que são relacionadas com a 
gestão da qualidade do produto e a eficácia do processo de desenvolvimento do software denominadas de problemas do software (percepção de dificuldade e dúvida ou incerteza no usuário) e defeitos do software (falha do produto).

A importância da qualidade de software é amplamente reconhecida e discutida em conjunto com os métodos ágeis que incorporaram práticas de qualidade no processo de desenvolvimento de software para obter um software de qualidade rapidamente e em harmonia com as mudanças rápidas dos requisitos do cliente (Arcos-Medina \& Mauricio, 2019). As metodologias de processos de desenvolvimento de software geram documentos com o objetivo de guiar a confecção do produto software garantido produtividade e qualidade, como por exemplo, o RUP (Rational Unified Process), o FDD (Desenvolvimento Dirigido a Funcionalidade), o XP (Programação Extrema) e o SCRUM (Pereira, 2014)

Apesar das dimensões da qualidade de Garvin (1987), inicialmente criadas para ser aplicadas nas indústrias de transformação física (conversão de matérias-primas em objetos físicos), elas podem ser aplicadas nas indústrias de software (que criam objetos lógicos), conforme apresentado no Quadro 2. Observa-se que, a partir dessas dimensões, a verificação da qualidade poderá ser quantitativa ou qualitativa.

\section{Quadro 2}

Dimensões da qualidade

\begin{tabular}{|c|c|}
\hline Dimensões & Conceito \\
\hline Qualidade de desempenho & $\begin{array}{l}\text { o software oferece tudo que foi especificado durante a criação do } \\
\text { documento de requisitos }\end{array}$ \\
\hline Qualidade dos recursos & o usuário final "se encanta" ao utilizar o software pela primeira vez \\
\hline Confiabilidade & o software está disponível com suas funcionalidades perfeitas, sem erros \\
\hline Durabilidade & $\begin{array}{l}\text { o software deverá ser mantido e corrigido sem causar outros erros em } \\
\text { cascata }\end{array}$ \\
\hline Conformidade & $\begin{array}{l}\text { codificação, projeto, padrões de software locais e externos, interface com } \\
\text { o usuário estão com os padrões aceitos e estabelecidos }\end{array}$ \\
\hline Estética & $\begin{array}{l}\text { o software apresenta uma certa "elegância", um fluir único aos olhos do } \\
\text { usuário }\end{array}$ \\
\hline Facilidade de Manutenção & $\begin{array}{l}\text { atualizações e correções, no software, devem ser feitas de maneira ágil e } \\
\text { rápida, sem causar outros males ao produto }\end{array}$ \\
\hline Percepção & $\begin{array}{l}\text { o usuário tem que ter uma opinião formada de que o software tem } \\
\text { qualidade, mesmo que não tenha }\end{array}$ \\
\hline
\end{tabular}

Fonte: Garvin (1987).

Ao longo do tempo, foram propostos muitos fatores e dimensões da qualidade para software, que tinham por objetivo definir certas características para dizer se um software tem qualidade ou não. Fatores da qualidade de McCall e da ISO 9126, conforme citados por Pressman (2011), concordam que um software de qualidade deve possuir os seguintes fatores: confiabilidade (ser confiável), usabilidade 
(fácil de usar), facilidade de manutenção (reparo e atualizações simples), funcionabilidade (fazer o que é para ser feito) e portabilidade (transferência de ambientes de software ou hardware de modo simples).

Para Sommerville (2011), o gerenciamento da qualidade de software possui três preocupações:

- No nível organizacional, o gerenciamento da qualidade se preocupará em criar um framework com processos organizacionais e padrões. São processos e padrões para o processo de desenvolvimento de software, que será utilizado, assim como para os requisitos e a codificação;

- Nível de projeto, o gerenciamento da qualidade se preocupará com a aplicação de processos específicos da qualidade, verificando que as saídas do projeto estão em conformidade com o especificado;

- Também, em nível de projeto, o gerenciamento da qualidade estará preocupado com a criação de um plano de qualidade, com metas para processos e padrões de software.

No nível organizacional, têm-se os chamados pilares da qualidade de software, que se trata da gestão da qualidade em si, e que segundo Bartié (2002) estes pilares são:

- Planejamento da qualidade: onde se cria e se arquiteta programas de gestão da qualidade;

- Garantia da qualidade: especificações de como garantir a qualidade mínima desejada;

- Controle da qualidade: maneiras de gerenciamento a qualidade.

Deste modo, pode-se dizer que há preocupação de como e quando aplicar ferramentas da qualidade de software em relação ao processo de desenvolvimento e ao produto, e com isso, as indústrias de software utilizam de padrões e modelos de qualidade de software aplicados ao produto ou ao processo. A ISO 9000-3 (diz respeito a processo de desenvolvimento e manutenção), a ISO 12207 (trata o ciclo de vida do software), o CMMI (Capability Maturity Model Integration ou Modelo de Capacidade e Maturidade Integrado, que avalia a maturidade dos processos da empresa) e o MPS.br (Melhoria do Processo do Software Brasileiro) são aplicados ao processo de desenvolvimento. Por sua vez, a ISO 12119 (especificação para pacotes de software), a ISO 9126 (específica métricas de software), são exemplos de padrões e modelos de qualidade utilizados nas indústrias de software (Vasconcelos et al., 2006; Koscianski \& Soares, 2007).

Aspectos que demostram que as indústrias de software possuem "processos formais e/ou informais que são implementados para produzir seus produtos de desenvolvimento de software" e esses produtos podem ser o produto final (sistemas computacionais, manuais, etc) ou artefatos 
intermediários (documentação de requisitos, diagramas de projeto, testes, etc) e várias técnicas e ferramentas de prevenção e de deteç̧ão são utilizadas afim de identificar defeitos nos produtos de trabalho. As técnicas de prevenção podem ser: treinamentos, planejamentos, modelagens, atuação do grupo de garantia de qualidade (SQA - System Quality Assurance), melhorias do processo. E para as técnicas de detecção estão disponíveis: a análise e compilação do código fonte, revisões em pares, testes e simulações, auditorias, verificações e validações. (Vasconcelos et al., 2006).

Como mencionado, atividades de prevenção e detecção fazem parte constantemente da qualidade de software e dentro destas atividades têm-se duas que merecem atenção: (i) testes e (ii) métricas de software.

Para Pressman (2011), os testes (i), presentes na gestão da qualidade de software, deve seguir um roteiro, com planejamento, projeto de casos de testes, execução dos testes, projeto de casos de testes, execução dos testes, coleta e avaliação dos dados para tomada de correções de erros. Existem vários tipos de testes de software, divididos nas seguintes classes de testes:

- Teste de Unidade: a interface do módulo do sistema é testada afim de garantir que as informações caminham corretamente para dentro e para fora da unidade do sistema em teste;

- Teste de Integração: verifica erros na integração de componentes de software;

- Teste de Regressão: toda vez que se adiciona módulos ao sistema de computação, pode-se ocorrer erros. Este teste tenta verificar erros causados por estes novos módulos;

- Teste Fumaça: É uma abordagem do deste de integração. É utilizado em projetos com prazos críticos.

As métricas de software (ii) utilizam a ação de medir (medição), técnicas de avaliação e métricas (Pressman, 2011). Para Vasconcelos et al. (2006), o uso de métricas de software pode trazer informações a respeito do "atendimento dos produtos de software aos requisitos especificados, desempenho do processo de desenvolvimento, esforço/custo despendido" entre outros indicadores.

Kan (2002) demostra a utilização de muitas métricas estatísticas (quantitativas) e qualitativas utilizadas nas métricas da qualidade. As métricas da qualidade são um subconjunto de métricas de software que tem seu foco no aspecto da qualidade do produto, do processo e do projeto. Em geral, as métricas da qualidade de software estão mais associadas com o processo de métricas do produto do que com as métricas do projeto. As métricas da qualidade do processo visam melhorar o desenvolvimento e a manutenção do software, por exemplo, a eficácia na remoção de defeitos, tempo de resposta do processo de correção. Por sua vez, as métricas da qualidade do projeto descrevem as 
características do projeto e de sua execução, por exemplo, número de desenvolvedores, padrão de pessoal ao longo do ciclo de vida, custo e estimativas sobre o cronograma do projeto.

\section{Método de pesquisa}

A primeira parte deste trabalho é uma pesquisa exploratória constituída por uma análise bibliométrica com o objetivo principal de criar uma classificação das ferramentas da qualidade que são citadas em artigos científicos que exploram a temática acerca da qualidade de software.

A análise bibliométrica é uma técnica quantitativa e estatística que permite medir a quantidade de publicação e a disseminação do conhecimento. Através de uma base de dados, pode-se realizar a contagem da quantidade de publicações sobre um tema, a quantidade e os autores mais citados, classificar os termos ou palavras mais utilizadas, verificar as datas ou ano que se concentraram o maior número de publicações, entre outros indicadores bibliométricos que podem ser criados e utilizados (Lopes et al., 2012; Coates et al., 2001).

Deste modo, pode-se criar indicadores bibliométricos. Esses indicadores têm o papel de apoio na conclusão final do objetivo ao qual se realiza uma análise bibliométrica. Assim, neste trabalho, os indicadores bibliométricos ajudam a criar evidências e afirmações a respeito de quais ferramentas da qualidade a engenharia de software se apoia para garantir qualidade em seus produtos e/ou processos. Os indicadores bibliométricos observados neste trabalho são apresentados no Quadro 3.

\section{Quadro 3}

Indicadores da pesquisa

\section{Indicadores}

Número de publicações sobre qualidade de software presente na base de busca

Número de publicações por ferramentas da qualidade utilizadas na qualidade de software

Autores com contribuições mais relevantes nas publicações

Ano de concentração das publicações com maior representatividade

Autores mais citados nas publicações

Palavras mais recorrentes nas publicações

Fonte: Autores (2020).

Segundo o guia de análise bibliométrica da Thomson Reuters (2008), a análise bibliométrica pode ser utilizada para:
- Medir a performance acadêmica;
- Realizar pesquisa acerca de uma temática;
- Entender a estrutura do desenvolvimento científico. 
As etapas sequenciais da análise bibliométrica aplicadas neste trabalho são descritas na Figura

1, e posteriormente detalhadas.

Figura 1

Etapas da análise bibliométrica

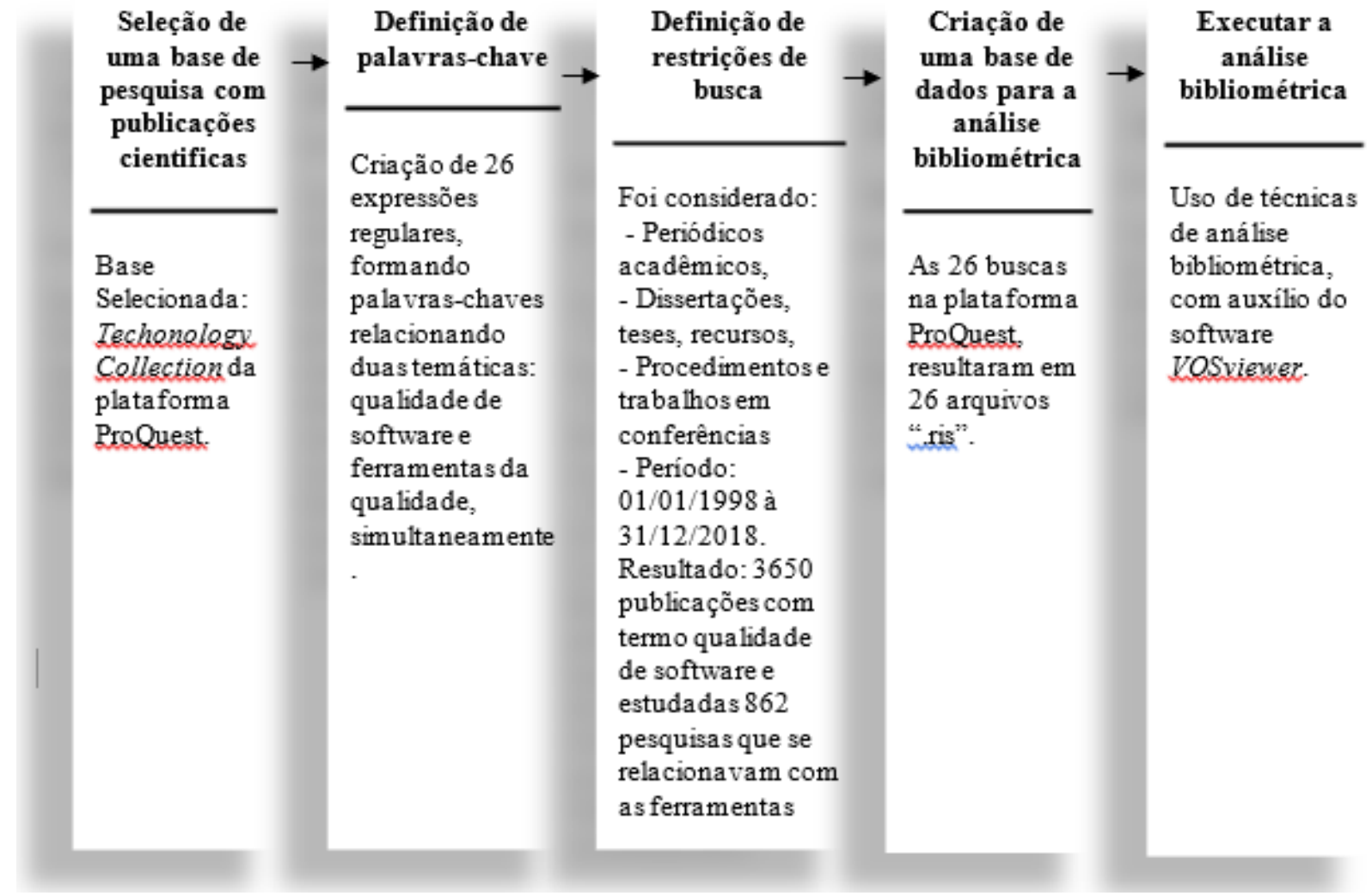

Fonte: Autores (2020).

- Seleção de uma base de pesquisa com publicações cientificas: Através do portal da Capes, foi selecionada a base Techonology Collection da plataforma ProQuest que contém 9 bases de dados com sub-bases, em diversas áreas do conhecimento. A base selecionada indexa literatura mundial sobre tecnologia e ciências aplicadas, como a computação, por exemplo.

- Definição de palavras-chave: foram utilizadas como palavras-chave a denominação das 26 ferramentas listadas no Quadro 1, sendo as pesquisas realizadas empregando tanto o termo em português quanto em inglês. Foram selecionadas publicações que tenham como temática a qualidade de software, e ao mesmo tempo, trabalhem com as ferramentas da qualidade. O Quadro 4 apresenta um exemplo das strings utilizadas, lógica aplicada para as demais denominações das ferramentas. 


\section{Quadro 4}

Exemplo de strings da pesquisa bibliométrica

\begin{tabular}{l|l|}
\hline \multicolumn{1}{|c|}{$\begin{array}{c}\text { Ferramenta da } \\
\text { qualidade }\end{array}$} \\
\begin{tabular}{|l|l|} 
Diagrama de \\
Causa e Efeito
\end{tabular} & $\begin{array}{l}\text { ("qualidade de software" AND "diagrama de ishikawa") OR ("qualidade de software" AND } \\
\text { ("quality software" AND "cause and effect diagram") }\end{array}$ \\
\hline $\begin{array}{l}\text { Folha de } \\
\text { Verificação }\end{array}$ & $\begin{array}{l}\text { ("qualidade de software" AND "folha de verificação") OR ("quality software" AND "check } \\
\text { sheet") }\end{array}$ \\
\hline $\begin{array}{l}\text { Gráfico de } \\
\text { Controle }\end{array}$ & $\begin{array}{l}\text { ("qualidade de software" AND "gráfico de controle") OR ("qualidade de software" AND } \\
\text { "carta de controle") OR ("quality software" AND "control letter") OR ("quality software" } \\
\text { AND "control chart") }\end{array}$ \\
\hline Histograma & ("qualidade de software" AND "histograma") OR ("quality software" AND "histogram") \\
\hline $\begin{array}{l}\text { Diagrama de } \\
\text { Dispersão }\end{array}$ & $\begin{array}{l}\text { ("qualidade de software" AND "diagrama de dispersão") OR ("qualidade de software" AND } \\
\text { "diagrama de correlação") OR ("quality software" AND "scatter diagram") OR ("quality } \\
\text { software" AND "correlation diagram") }\end{array}$ \\
\hline \multicolumn{2}{|l|}{ Fonte: Autores (2020). } \\
\hline
\end{tabular}

- Definição de restrições de busca: Houve a necessidade de definir um intervalo de tempo e os tipos de publicações que permitiu construir a base de dados da análise bibliométrica. As restrições para este trabalho foram definidas conforme o Quadro 5.

\section{Quadro 5}

Restrições da pesquisa bibliométrica

\begin{tabular}{|c|c|}
\hline \multicolumn{2}{|l|}{ Restrições } \\
\hline Datas das publicações & 01/01/1998 à 31/12/2018 \\
\hline $\begin{array}{l}\text { Tipos de publicações aceitas } \\
\text { sem restrição de idioma }\end{array}$ & $\begin{array}{l}\text { _Periódicos Acadêmicos; } \\
\text { _ Dissertações, Teses e Artigos; } \\
\text { _ Procedimentos e trabalhos de conferências; } \\
\text { _ Revistas. }\end{array}$ \\
\hline Tipos de publicações não aceitas & $\begin{array}{l}\text { _Periódicos comerciais; } \\
\text { _ Relatórios; } \\
\text { _ Livros; } \\
\text { _Blogs, podcast e sites; } \\
\text { _ Documentos de trabalho; } \\
\text { _ Outras fontes. }\end{array}$ \\
\hline
\end{tabular}

Fonte: Autores (2020).

- Criação de uma base de dados para a análise bibliométrica: Para realizar uma análise bibliométrica, é necessário ter uma base de dados com informações de publicações com a temática desejada. Neste trabalho, esta base de dados foi formada por resultados de buscas na plataforma ProQuest utilizando as chaves conforme exemplificado no Quadro 4. Assim, a base de dados é formada por 26 arquivos em formato ".ris" que foram exportadas diretamente da plataforma ProQuest. 
A busca com a palavra-chave [("qualidade de software") OR ("quality software")] demostrou que há 3.560 publicações na plataforma que trabalha com a temática da qualidade de software.

- Executar a análise bibliométrica: Para realizar uma análise bibliométrica, pode-se utilizar softwares bibliométricos que processam uma base de dados (geralmente arquivos ".ris") com informações de buscas de publicações com características desejadas em comum. Estes softwares extraem, utilizando metodologias internas apropriadas, informações quantitativas que o usuário poderá utilizar como indicadores bibliométricos, conforme sua necessidade, para realizar conclusões a respeito do que já foi publicado sobre um tema. Neste trabalho, o software bibliométrico designado foi o VOSviewer 1.6.11 e os gráficos construídos com os indicadores bibliométricos extraídos do VOSviewer 1.6.11 é construído a partir do software Excel.

\section{Resultados da Pesquisa}

\subsection{Número de publicações por ferramentas da qualidade aplicadas a qualidade de software}

A partir das pesquisas realizadas e da formulação do banco de dados bibliométrico para identificar cada ferramenta da qualidade utilizada na qualidade de software, obteve-se um total de 862 publicações. Foi possível classificar e elaborar o gráfico identificando as ferramentas mais citadas nestas publicações, conforme a Figura 2.

Figura 2

Frequência de citações $x$ ferramentas da qualidade

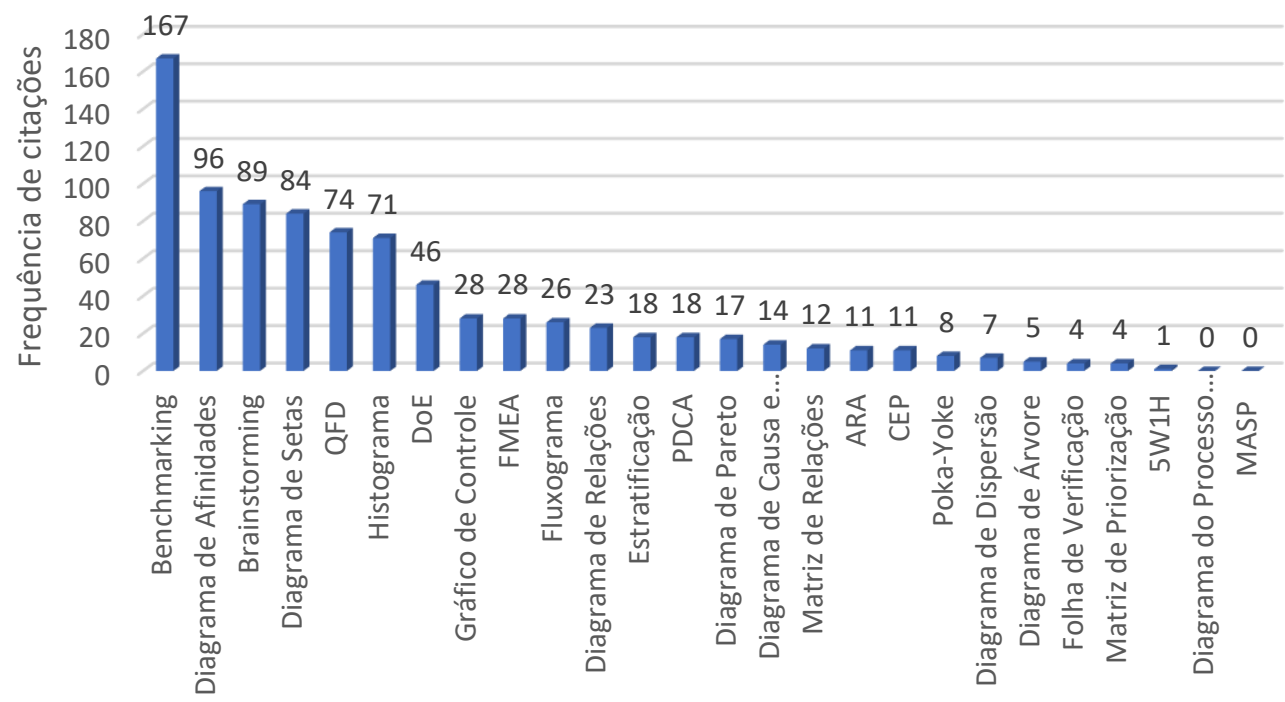

Ferramentas da Qualidade

Fonte: Autores (2020). 
$\mathrm{Na}$ Figura 2, consta as ferramentas da qualidade mais citada nas publicações sobre qualidade de software. O Benchmarking, o Diagrama de Afinidades e o Brainstorming foram os mais citados, respectivamente. Já o Masp e o Diagrama do Processo Decisório não foram citados. Uma das razões pode ser devido a aplicações de outras ferramentas como o PDCA no caso do MASP, por trazer um resultado semelhante ao MASP, e no caso do Diagrama do Processo Decisório, por ser uma ferramenta pouco explorada e conhecida, provavelmente as empresas de software utilizam um fluxograma, em seu lugar, pois o fluxograma também traz informações sobre as etapas a serem consideradas para se chegar a um objetivo desejado, assim como o Diagrama do Processo Decisório.

\subsection{Autores com maior número de publicações}

Verificando os pesquisadores, na base de dados, os que mais publicam sobre a utilização de ferramentas da qualidade na avaliação de software, tem-se que a maior produtividade em termos de publicação é do autor Mario Piattini $(n=119)$, seguido por Alain Abran $(n=116)$, e por Ali Javed e Mahmood Niazi $(n=68)$. Na Figura 3, pode-se visualizar os 15 autores que mais publicaram sobre o assunto.

\section{Figura 3}

Número de publicação por autor

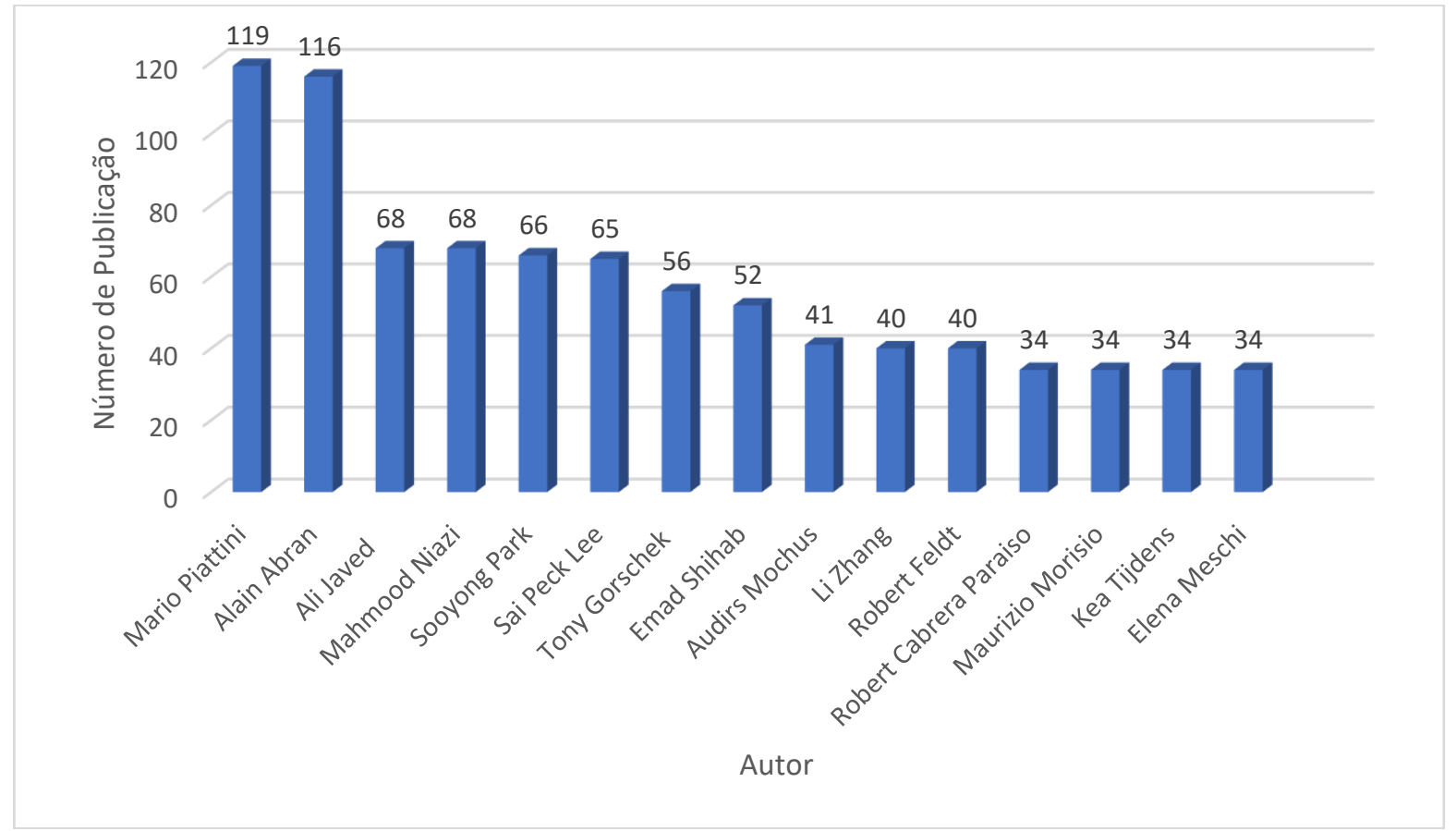

Fonte: Autores (2020). 


\subsection{Análise bibliométrica pelo método co-authorship (co-autoria)}

Uma das análises bibliométricas disponíveis é a chamada análise co-authorship ou análise de co-autoria. Para Basso, Rech e Baseggio (2013), quando mais de um autor assina uma publicação eles se tornam co-autores e quando dois autores são co-autores em um ou mais artigos eles são chamados de colaboradores. A co-autoria é um indicador que avalia a colaboração intelectual entre autores.

Essa análise verifica na base de dados os coautores das publicações, trazendo indicadores com nomes de autores que trabalham juntos sobre um tema. A análise é importante pois mostra uma rede de autores preocupados com uma temática em comum.

Configurando para verificar até 25 autores em uma publicação e o número mínimo de uma publicação por autor e trabalhando com um total de 200 autores, foi permitido a construção de diagramas que permitiram extrair informações sobre os autores do tema estudado.

$\mathrm{Na}$ Figura 4, identifica-se que Mario Piattini e Alain Abran foram os dois autores que mais colaboraram, cada um com seu grupo de co-autoria e com o seu tema em estudo específico. Estes dois autores apresentam os "círculos" maiores e destacados os demais ela sua magnitude, quando se observa a Figura 4. Quanto maior o tamanho do "círculo" na rede, maior a colaboração do autor sobre o tema. Cada agrupamento de círculos indica os autores que trabalharam juntos em publicações através de colaboração. Cada grupo isolado indica um tema distinto que é explorado nas publicações. 


\section{Figura 4}

Rede de visualização de autor em colaboração

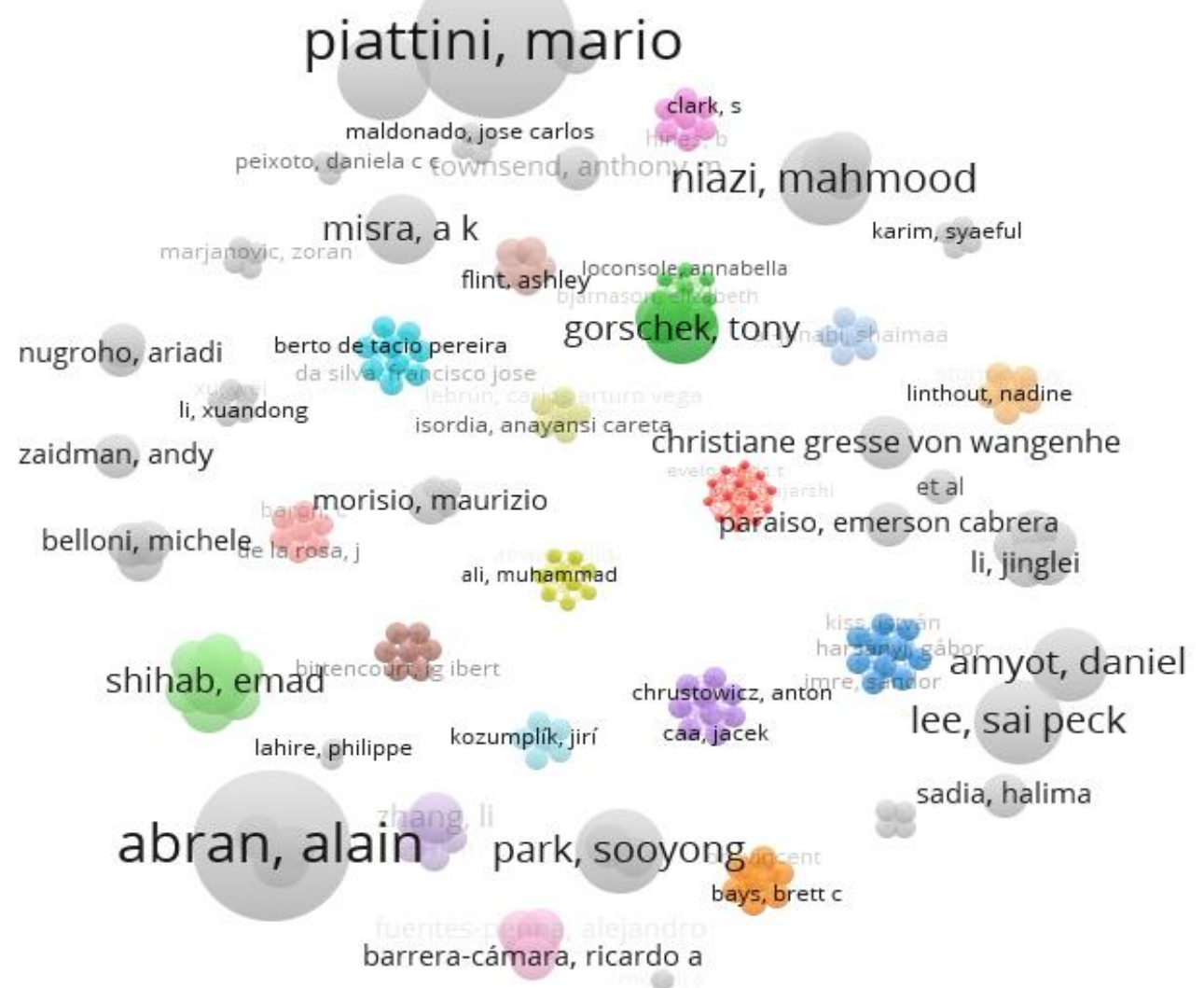

Fonte: VOSviewer 1.6.11 (2020).

No caso do Alain Abran observa-se que existem uma sobreposição no círculo que contém o autor e verifica-se na rede de co-autoria que o autor colabora com Oscar Pastor, Witold Suryn e Adel Khelifi.

Em relação ao lado direito do círculo do autor Emerson Cabrera Paraiso, nota-se um círculo, em vermelho, que chama a atenção por ser composto com muitos vértices e outros pequenos círculos. Este círculo concentra um número grande de autores de menor destaque, em relação a temática aqui estudada, que colaboram entre si. Aplicando, novamente, o recurso de zoom, verifica-se detalhes deste grupo de co-autores, como pode ser observado na Figura 5. Neste caso, nota-se que existem 14 autores em colaboração e uma grande concentração de ligações entre eles, provavelmente ligações de colaborações em uma temática de estudo única que os envolve de algum modo. 
Figura 5

Rede de visualização de um grupo autor em colaboração em destaque

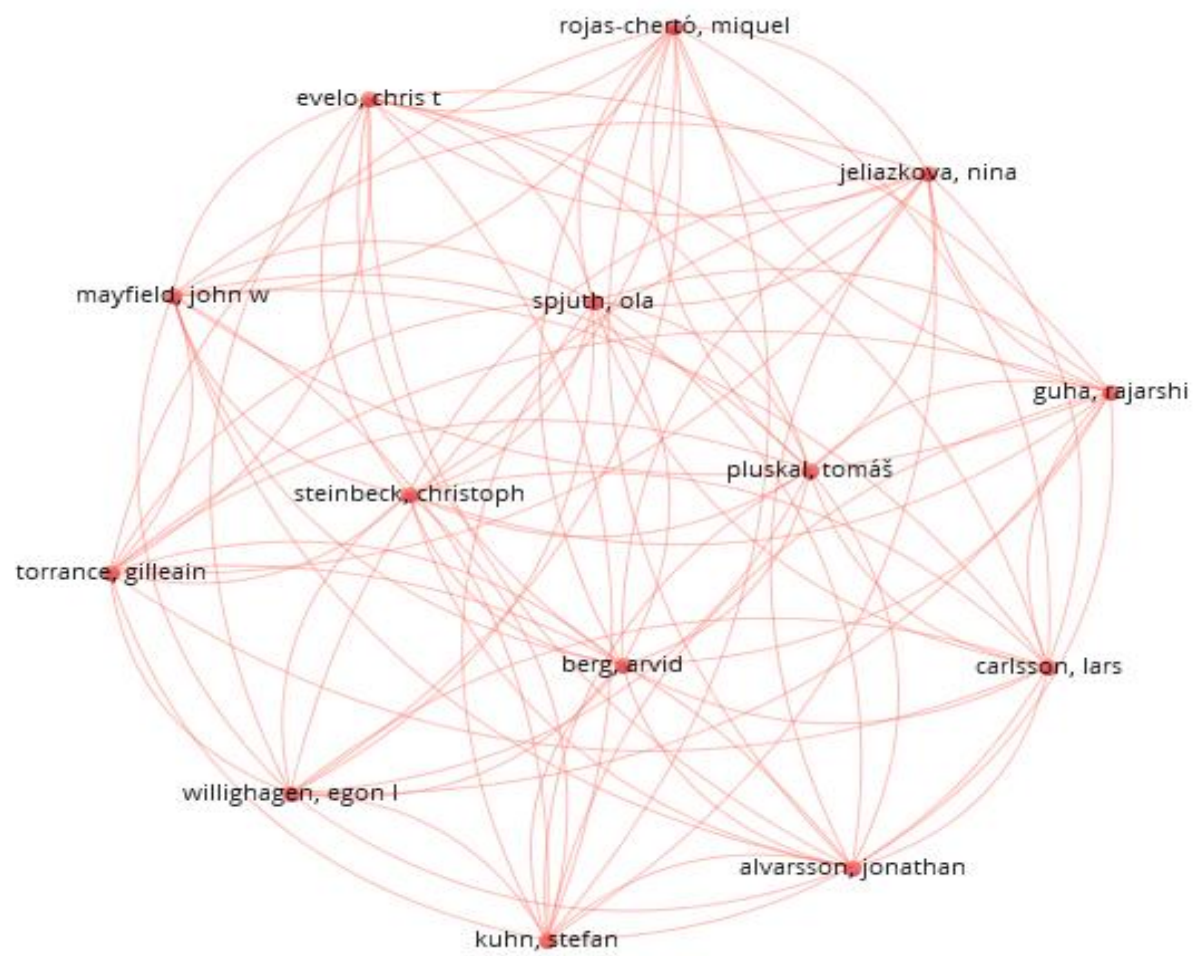

Fonte: VOSviewer 1.6.11(2020).

A Figura 6 representa o digrama de rede de visualização de sobreposição de co-autoria. 0 diagrama relaciona o ano em que os autores realizaram publicações em co-autoria. Cada aglomerado de círculo é uma temática publicada e cada cor dos círculos indica o ano que ocorreram as publicações. Com isso, por exemplo, pode-se dizer que a temática do autor Alain Abran e seus colaboradores em seu tema, fizeram publicações em meados do ano de 2010. Por sua vez, Mario Piattini, o autor mais expressivo em número de publicações, fez sua publicação em torno do ano de 2012. Também pode-se dizer que os grandes núcleos de temáticas publicaram em anos próximos, pois não há muitas intercessões de círculos com cores distintas. 
Figura 6

Rede de visualização de sobreposição

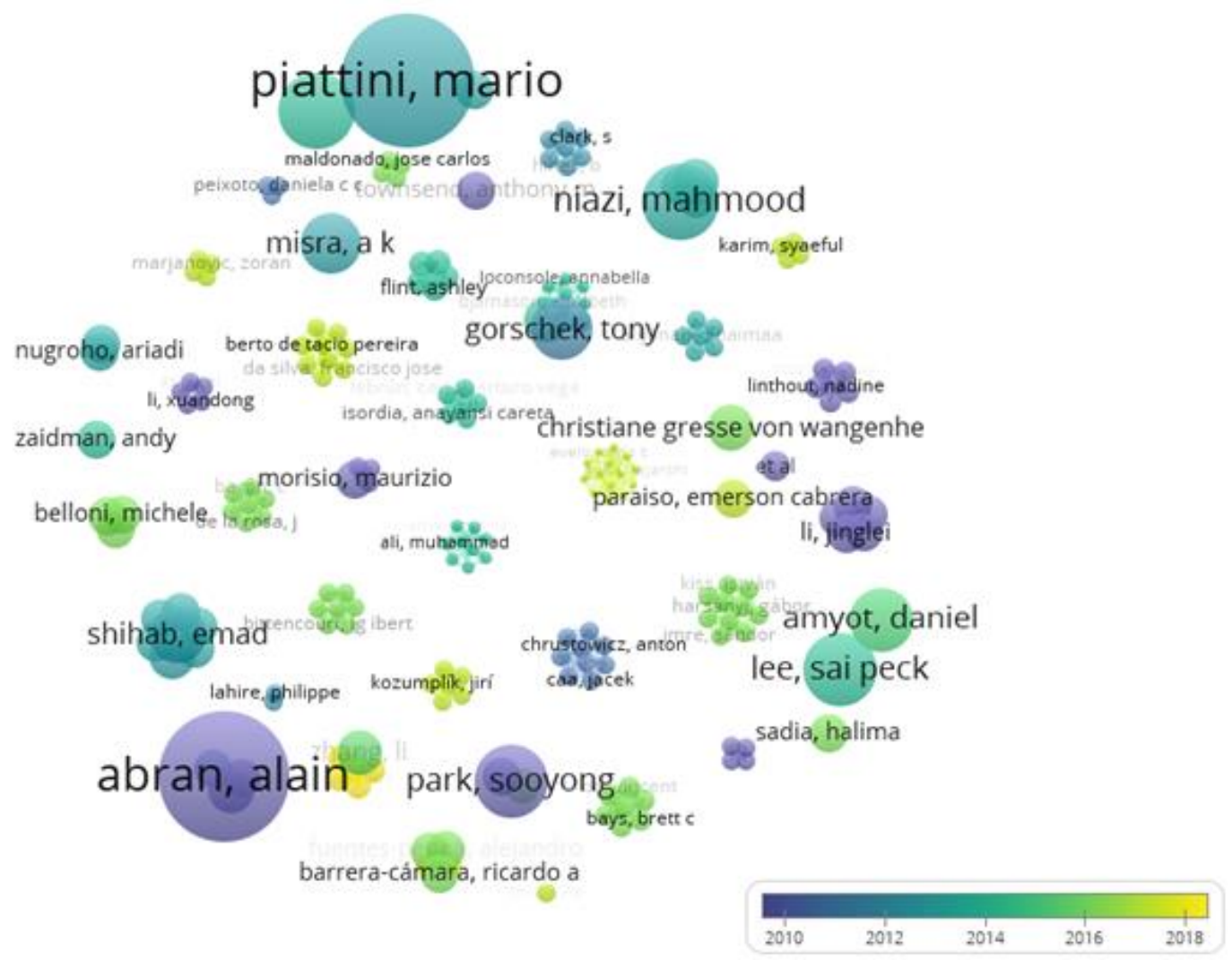

Fonte: VOSviewer 1.6.11 (2020).

Observando as Figuras 5 e 6, nota-se que a co-autoria destas publicações se concentram por volta do ano de 2018, sendo uma temática provavelmente nova, indicando uma possível tendência quanto ao uso das ferramentas da qualidade aplicadas na qualidade de software.

Realizando uma busca nos arquivos da base bibliométrica, por 4 co-autores aleatórios (Stefan Kuhn, Gilleain Torrence, Rajarshi Guha e Nina Jeliazkova) entre os que estão na rede da Figura 5, concluise que eles colaboram em publicações sobre as seguintes ferramentas da qualidade aplicadas a qualidade de software: PDCA, QFD, Poka-Yoke, FMEA, DoE. Além disso, estas publicações são de 2017, demonstrando o período que estes autores colaboram.

Portanto, pode-se dizer que as ferramentas da qualidade PDCA, QFD, Poka-Yoke, FMEA e DoE representam uma tendência em publicações científicas que relacionam ferramentas da qualidade aplicadas à qualidade de software, pois apresentam um grande número de autores que colaboraram de alguma forma, recentemente, utilizando tais ferramentas.

$\mathrm{Na}$ análise dos dados é possível verificar que existem grupos de autores que colaboram são os que mais se destacaram em números de citações, como por exemplo como Alain Abran, Mohmood Niazi e Enad Shihab. 
A Figura 7 destaca o indicador de Quantidade de Citações dos autores e conclui-se que os sete autores mais citados obtiveram um total de 204 citações cada, seguidos de um segundo grupo de autores com 153 citações a eles.

Figura 7

Quantidade de citações $x$ autor

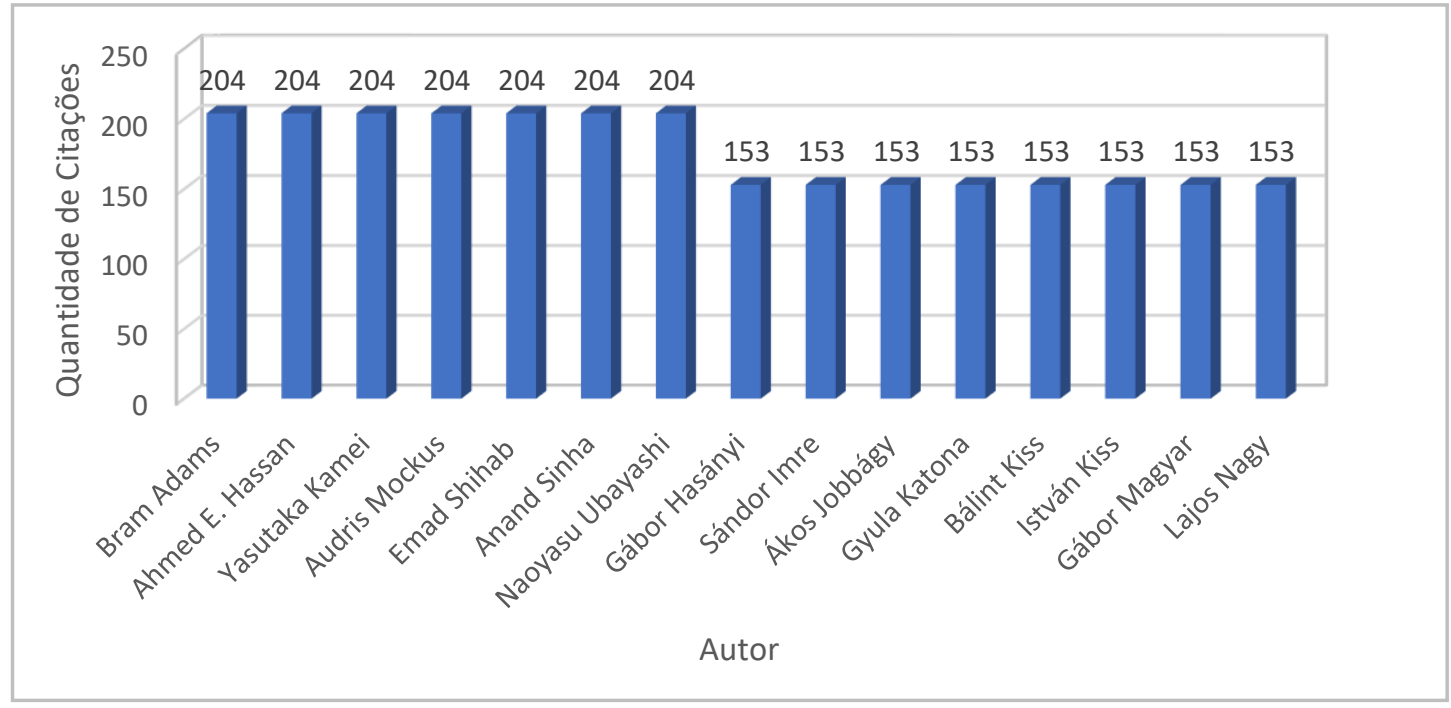

Fonte: Autores (2020).

É possível verificar os autores que se relacionam entre si, de alguma forma, como mostra a Figura 8. No tema de pesquisa existe um grupo com 14 autores que interagem entre si. As linhas de ligações, no diagrama, indicam os relacionamentos entre estes grupos de autores. 
Figura 8

Rede de visualização com interelacionamentos

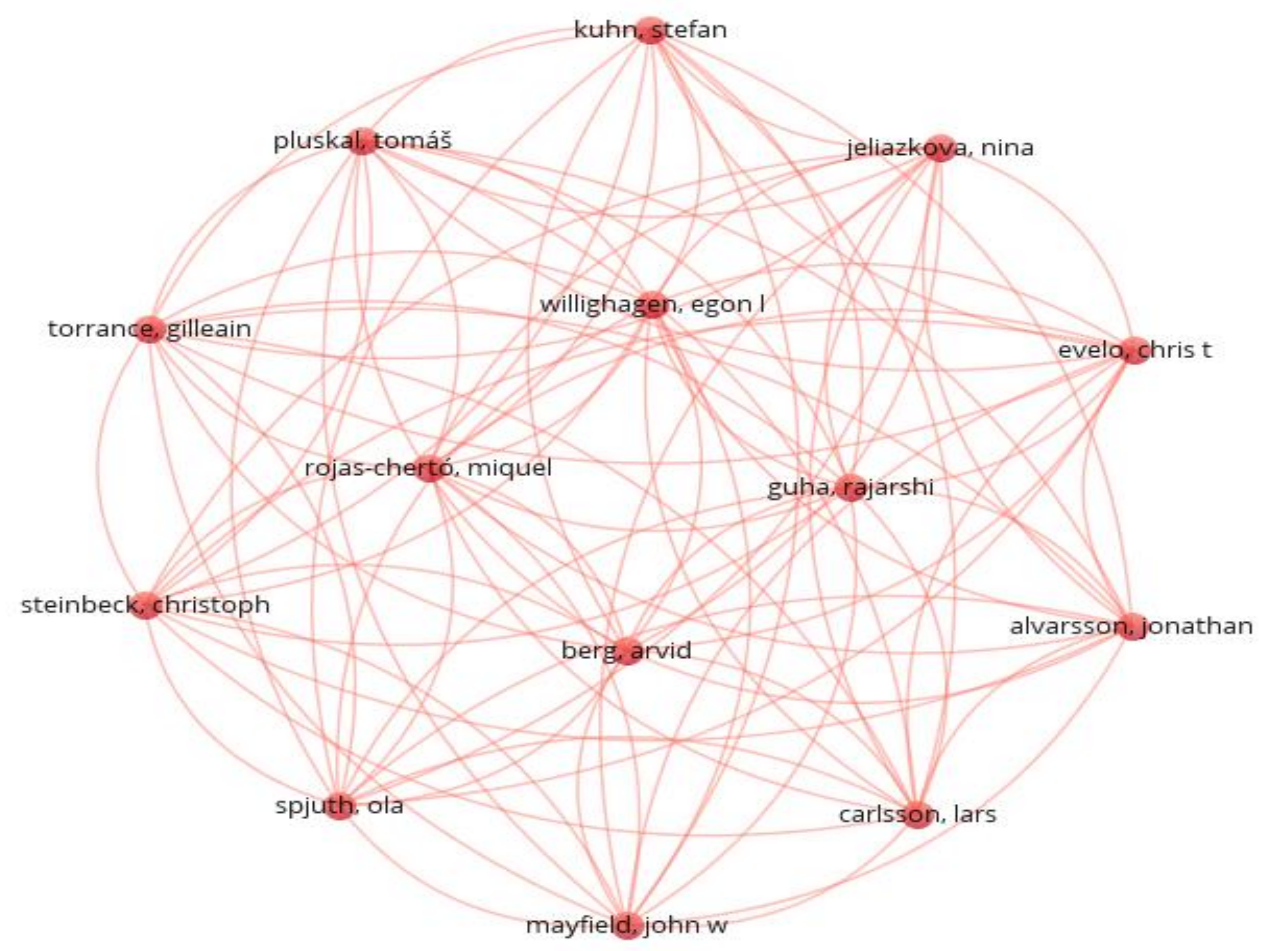

Fonte: VOSviewer 1.6.11 (2020).

\subsection{Análise Bibliométrica pelo método co-occurrence}

Segundo Zupic \& Čater (2015), o método de co-occurrence ou co-ocorrência de palavras é uma técnica de análise de conteúdo que segue a seguinte lógica: se as palavras se repetem em diversos documentos, os conceitos relacionados à esta palavra também estão relacionados de alguma forma.

Esta metodologia busca nas publicações as palavras mais recorrentes. Para esta análise, as mesmas configurações da análise foram mantidas, explorando um total de 200 palavras.

Inicialmente é possível criar um indicador para verificar as palavras mais recorrentes nas publicações, conforme a Figura 9. Neste caso, observa-se que o computers-software, studies e software engineering são as três palavras mais recorrentes nas publicações. 
Figura 9

Gráfico número de recorrência x palavra mais recorrente

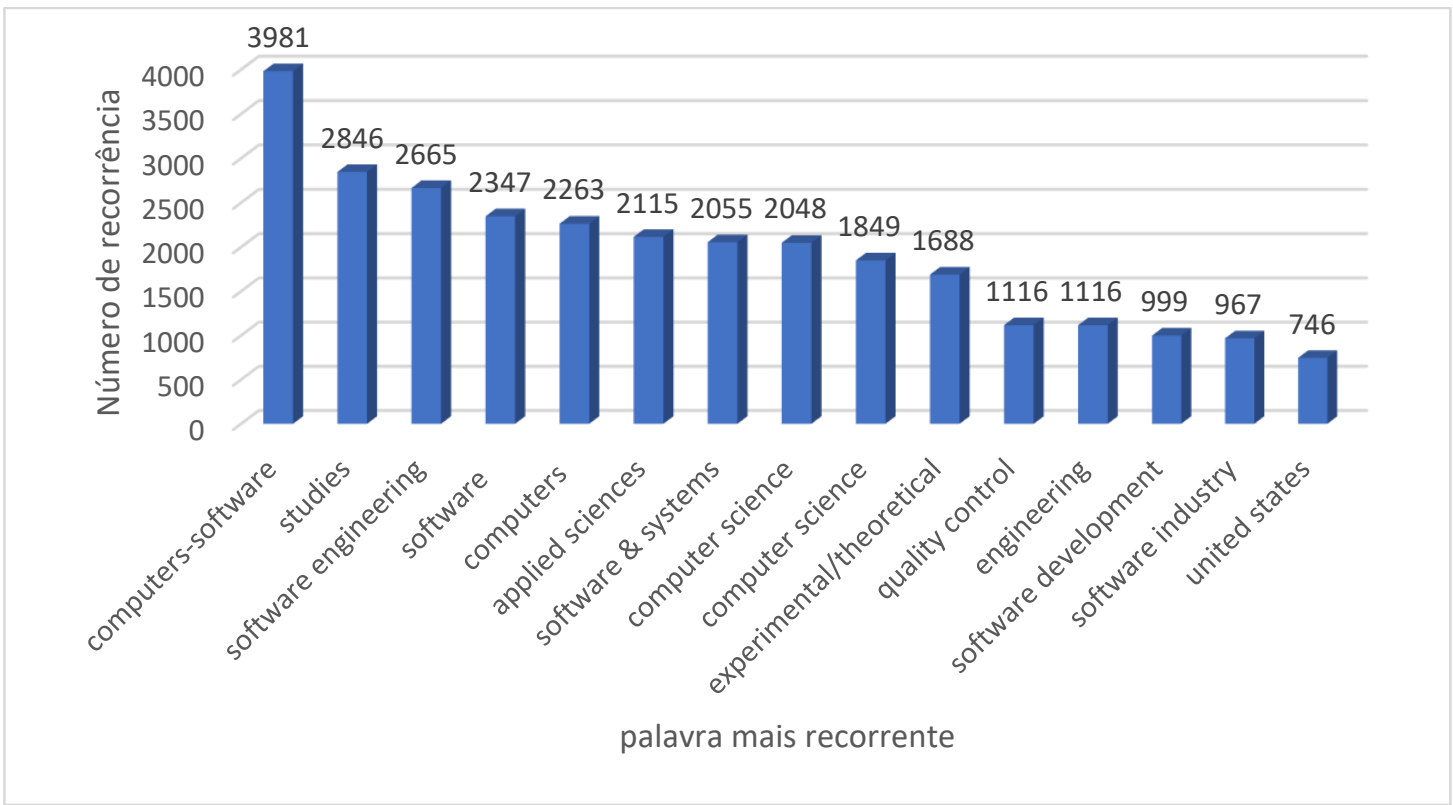

Fonte: Autores (2020).

Apesar das palavras mais recorrentes não estarem relacionadas exatamente com as ferramentas da qualidade, pode-se observar palavras diretamente associadas com tais ferramentas, como por exemplo, statistical analysis que remete fortemente a ferramenta de Controle Estatístico do Processo (CEP). Também se notou outras palavras ligadas aos processos de qualidade e qualidade de software, como por exemplo, quality of service e usuability, respectivamente. Desta forma, as palavras utilizadas no universo da engenharia de qualidade, das ferramentas da qualidade e da qualidade de software, presentes na base bibliométrica, estão relacionadas de algum modo, e assim, garantindo que a pesquisa bibliométrica não se desvie da temática proposta.

Pelo método co-occurrence foi produzido o diagrama de rede de visualização, conforme Figura 10. Neste caso, é possível observar pelo tamanho da fonte das palavras que as palavras mais recorrentes nas publicações foram computers-software, software \& systems, software, computer science, entre outras. Além disso, é possível notar a formação de quatro principais clusters (aglomerados de palavras com grande número de relacionamentos, ou ligações, entre si, presentes na base bibliométrica), sendo de cor azul relacionado a qualidade e conformidade de software, de cor verde envolvendo o desenvolvimento, linguagem de programação, algoritmos, de cor amarelo voltado para ciência da computação, e de cor vermelho relacionado a trabalhos acadêmicos que envolvem por exemplo revisão da literatura e estudos de caso. Assim, nota-se a existência de relacionamentos de palavras ou termos utilizados nas áreas de computação, engenharia de software e engenharia da qualidade, relacionandose, desde modo, ligando de alguma forma, essas áreas do conhecimento, com palavras que remetem 
as ferramentas da qualidade, reforçando mais uma vez a validade da análise bibliométrica sem fugir da temática proposta. Observa-se, também que quanto mais longe os núcleos dos clusters estão, menos importante e significativo será estes relacionamentos, assim existem distância muito próximas de clusters com palavras da engenharia de software e da engenharia de qualidade.

Figura 10

Rede de visualização de palavras com relacionamentos

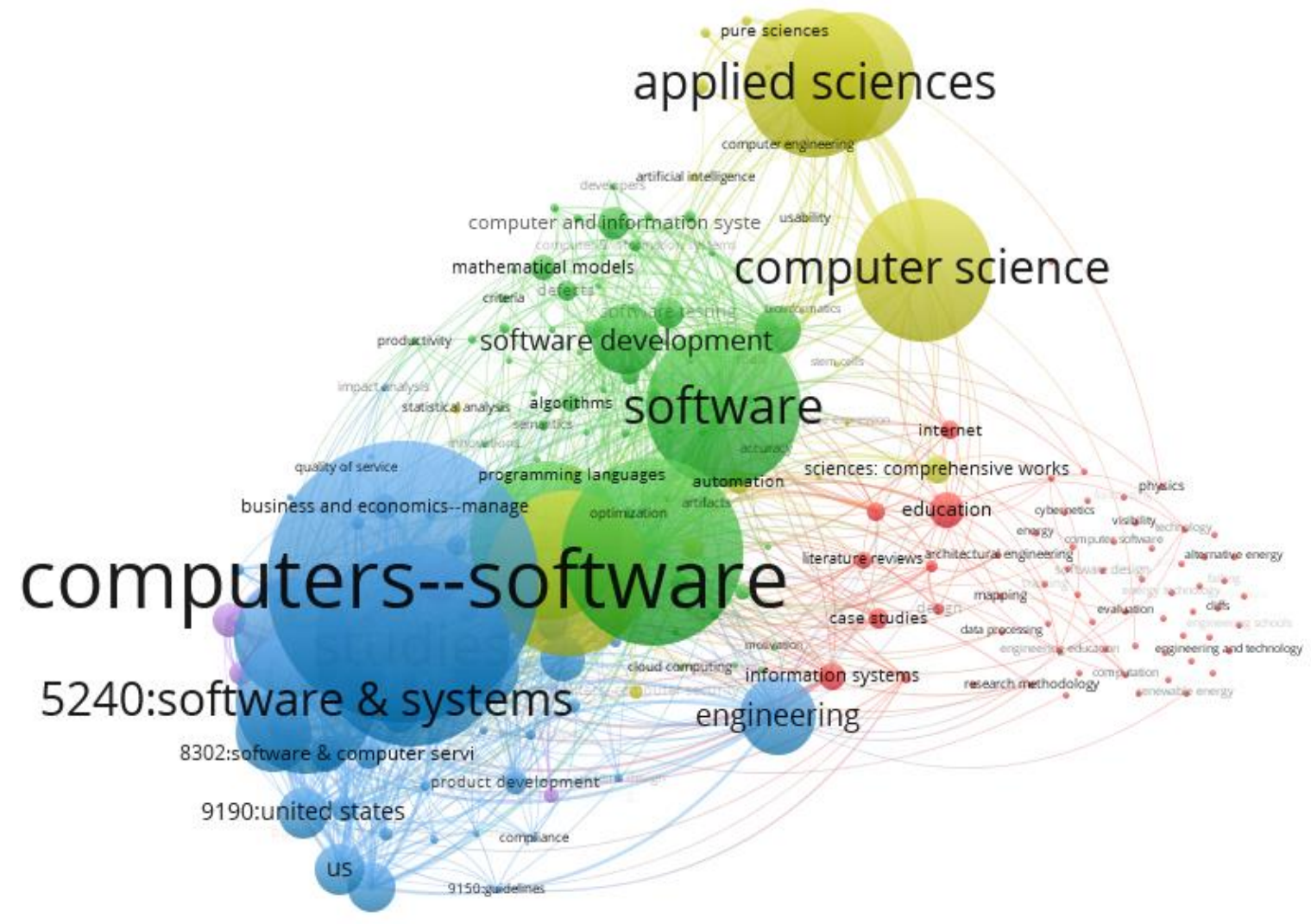

Fonte: VOSviewer 1.6.11(2020).

O diagrama também representa as ligações existentes entre o relacionamento de palavras importantes, e através dessa informação foi possível criar o indicador de palavras que mais se ligam com outras, conforme Figura 11. E, studies, software enginnering, software \& systems são as três palavras com maior ligação com outras. 
Figura 11

Palavras com maior quantidade de ligação

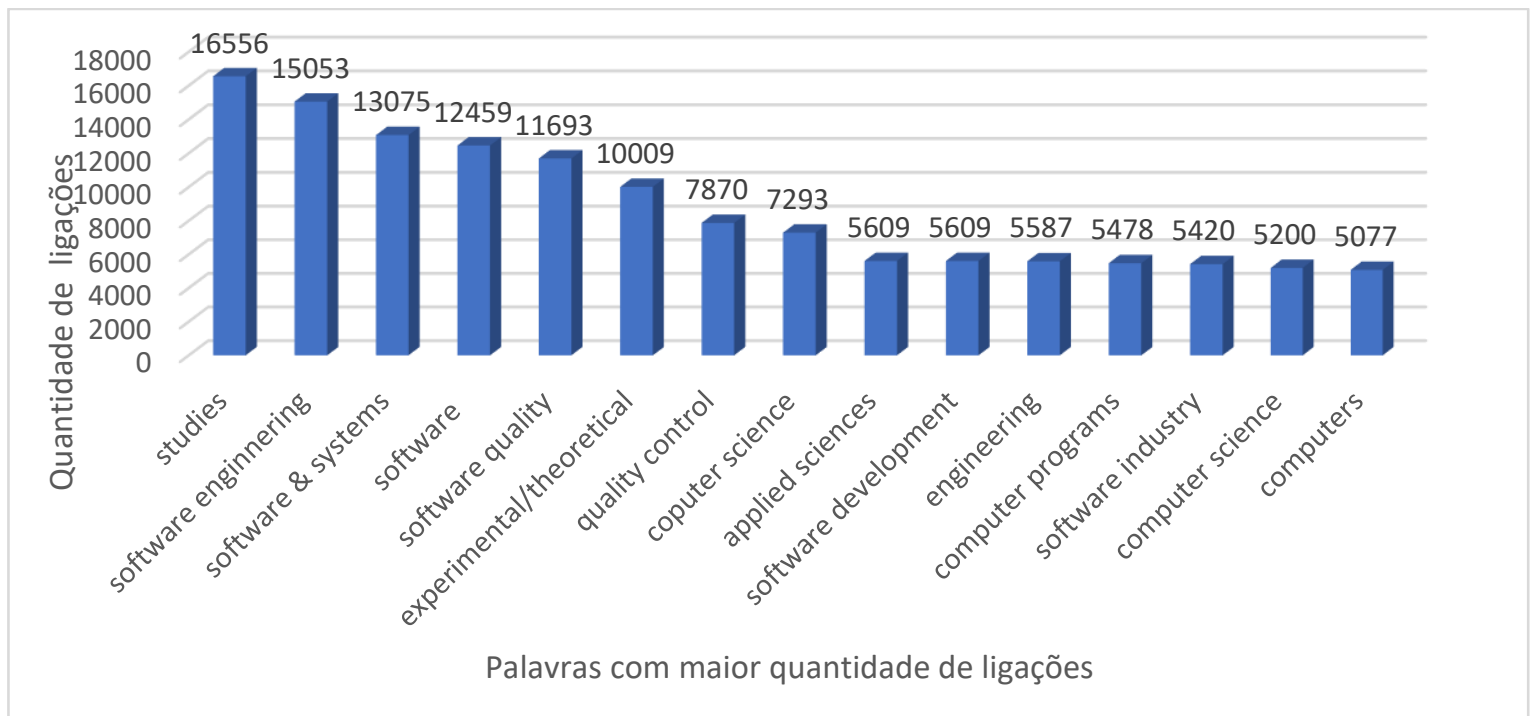

Fonte: Autores (2020).

O diagrama de rede de visualização de intensidade é destacado na Figura 12. Observa-se que existem 5 núcleos com tonalidade em amarelo ao redor das 5 palavras mais citadas nas publicações. Existem outras palavras ao redor dos núcleos de tonalidades mais fortes, que são palavras que estão relacionadas de algum modo com as principais palavras mais citadas. Por exemplo, a palavra computerssoftware, de maior predominância de citação tem dentro do seu núcleo a palavra software \& system, isso significa que de alguma forma as duas palavras se complementam ou se relacionam de alguma forma nas publicações. 


\section{Figura 12}

Rede de visualização de densidade de palavras

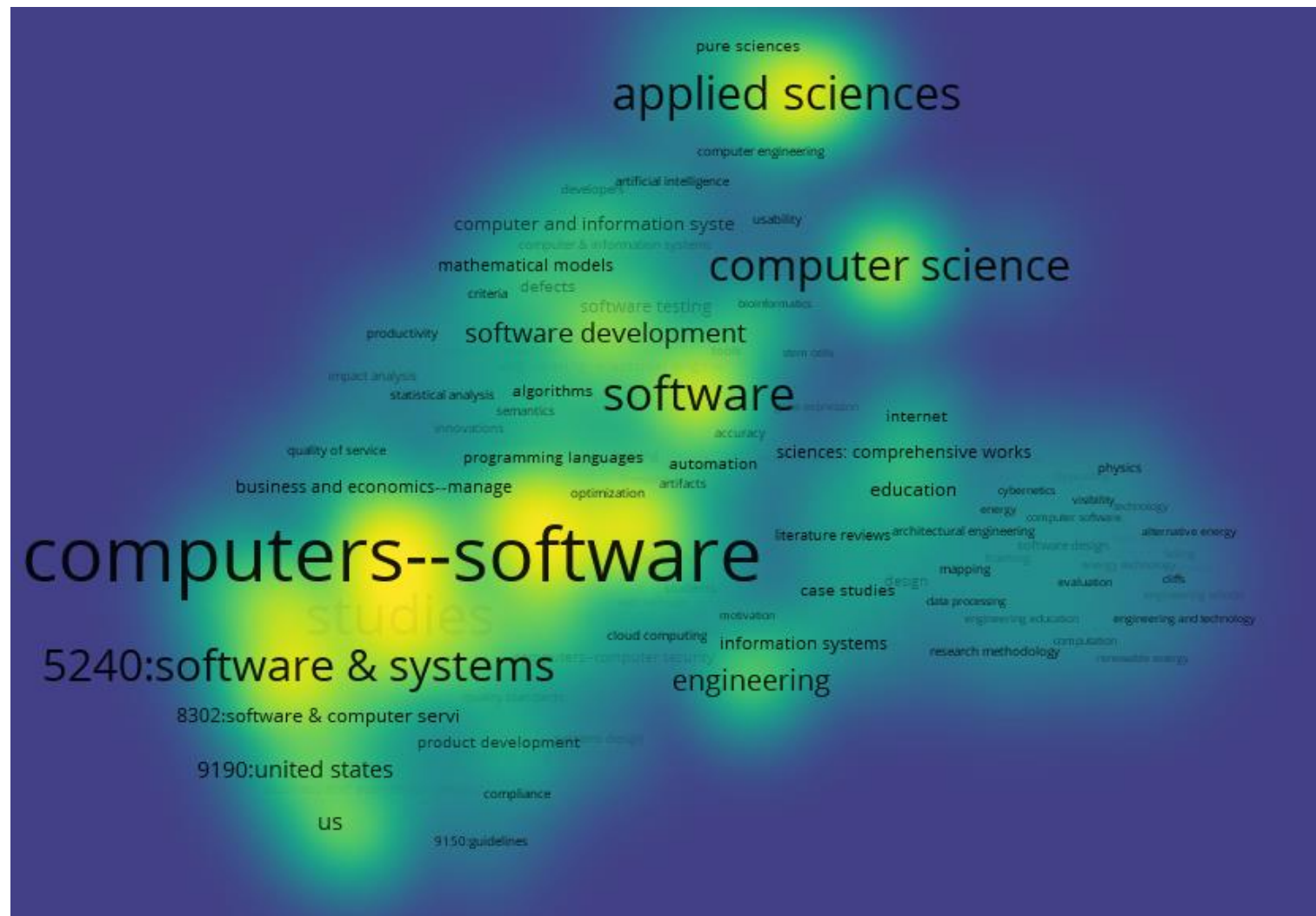

Fonte: VOSviewer 1.6.11 (2020).

\subsection{Discussões}

Durante o levantamento dos artigos para a análise bibliométrica não foram identificados artigos similares que permitissem uma comparação dos resultados desta pesquisa com os de literatura internacional, o que enfatiza a originalidade do presente estudo. Quanto à estudos nacionais, na base ProQuest também não foram identificados trabalhos similares. Apesar de não ser o foco deste estudo é de conhecimento que Perucci e Campos (2016) realizaram um estudo bibliométrico sobre técnicas de qualidade aplicadas a software, no qual identificaram modelo o CMM/ CMMi e a norma ISO 9126 como relevantes mundialmente para auxiliar no controle de qualidade. Assim, o uso conjunto das ferramentas e técnicas podem contribuir significativamente com a qualidade do processo de desenvolvimento de software.

\section{Considerações finais}

O presente trabalho propôs verificar o uso das ferramentas da qualidade em processos de qualidade de software, por meio de uma análise bibliométrica. Dessa forma, verificou-se que as ferramentas benchmarking e brainstorming estão entre as mais utilizadas, sendo uma das possíveis 
causas a sua importância para coletar ideias para o planejamento das atividades, e a criação do produto. Já o fluxograma é uma ferramenta menos relevante cientificamente identificada nas pesquisas.

Foi observado em trabalhos do ano de 2018, a citação das ferramentas PDCA, QFD, Poka-Yoke, FMEA e DoE. Isso pode ser um indicativo de tendência de que a indústria de software está incorporando processos de melhorias mais robustos e alinhados a necessidades do processo de produção do software.

A pesquisa apresenta o estado da arte do tema, contribuindo para melhorar a compreensão da interface entre as áreas de engenharia de produção e engenharia de software ao apresentar as ferramentas que inicialmente foram desenvolvidas para indústrias de manufatura e que são aplicados em melhorias de qualidade de software. Além disso, o trabalho contribui com a prática, pois permitirá às empresas conhecerem e ter uma referência do que tem sido estudo nos últimos anos. Por fim, o trabalho verificou a falta de uma influência ou uma produção significativa de pesquisadores brasileiros na temática que poderiam ajudar a entender o contexto das ferramentas em empresas nacionais.

Assim, para trabalhos futuros, propõe-se um estudo mais detalhado do uso das ferramentas da qualidade nos processos da qualidade de software, incluindo um levantamento junto às empresas, seguindo métodos de pesquisa baseado em conceitos estatísticos.

É válido mencionar que os resultados e análises realizadas não esgotam o assunto. As limitações do estudo são relacionadas com a própria aplicação de indicadores bibliométricos que pode levar a desconsiderar pesquisas mais recentes como importantes para a área de conhecimento.

\section{Referências}

Abbott, L. (1995). Quality and Competition. New York: Columbia University Press.

ABES - Associação Brasileira de Empresas de Software. Dados do Setor: Estudo 2019 / Dados 2018. Disponível em: http://www.abessoftware.com.br/dados-do-setor/estudo-2019--dados-2018

Almomani, M. A., Basri, S., \& Gilal, A. R. (2018). Empirical study of software process improvement in Malaysian small and medium enterprises: The human aspects. Journal of Software: Evolution and Process, 30(4), 1-15. https://doi.org/10.1002/smr.1953

Arcos-Medina, G., \& Mauricio, D. (2019). Aspects of software quality applied to the process of agile software development: a systematic literature review. International Journal of System Assurance Engineering and Management, 10, 867-897. https://doi.org/10.1007/s13198-01900840-7

Bartié, A. (2002). Garantia de Qualidade de Software: adquirindo maturidade organizacional. Rio de Janeiro: Elsevier.

Basso, K., Rech, E., \& Baseggio, H. W. (2013). Análise bibliométrica da coautoria em marketing no Brasil: evidências a partir de artigos publicados em eventos promovidos pela ANPAD entre 2000 e 2009. Disponível em: http://revistaseletronicas.pucrs.br/fo/ojs/index.php/face/article/view/18256 
Benabdellah, A.C., Benghabrit, A., \& Bouhaddou, I. (2020). Design for relevance concurrent engineering approach: integration of IATF 16949 requirements and design for $X$ techniques. Research in Engineering Design, 31, 323-351. https://doi.org/10.1007/s00163020-00339-4

Bonanomi, R. C., da Silva, W. V., Del Corso, J. M., \& Duclós, L. C. (2010). Aplicação da teoria grey e FMEA - análise dos modos de falha e efeitos na priorização de riscos de projetos de desenvolvimento de software produto. Revista Gestão Industrial, 6(4), 70-92. https://doi.org/10.3895/S1808-04482010000400004

Broh, R. A. (1982). Managing Quality of Higher Profits. New York: McGraw-Hill.

Carvalho, M. M., \& Paladini, E. P. (2012). Gestão da Qualidade -Teoria e Casos. 2a. ed. Rio de Janeiro: Elsevier.

Castello, J., de Castro, R., \& Marimon, F. (2020). Use of quality tools and techniques and their integration into ISO 9001: A wind power supply chain case", International Journal of Quality \& Reliability Management, 37(1), 68-89. https://doi.org/10.1108/IJQRM-07-2018-0171

Chauhan V., Gupta, D. L., \& Dixit, S. (2014). Role of Software Metrics to Improve Software Quality. International Journal of Computer Science and Information Technologies, 5(3), 4167-4170. Disponível em: https://citeseerx.ist.psu.edu/viewdoc/download?doi=10.1.1.589.4656\&rep=rep1\&type=pdf

Chaos (2015) - Standish Group 2015. Chaos report-Q\&A with Jennifer Lynch. Disponível em: https://www.infoq.com/articles/standish-chaos-2015

Coates, V., \& Farooque, M. (2001). On the Future of Technological Forecasting. North-Holland: Elsevier Science.

Corrêa, H. L., \& Corrêa C. A. (2012). Administração de Produção e Operações. 3ạ. ed. São Paulo: Editora Atlas.

Crosby, P. B. (1984). Cutting the Cost of Quality. Industrial Education Institute.

da Silva, T. T. L., \& Barbosa, A. F. B. (2017). Evolução da norma ISO 9001: uma análise comparativa. Revista de Engenharia e Pesquisa Aplicada, 2(4), 56-66. https://doi.org/10.25286/repa.v2i4.718

Deming, W. E. (1990). Qualidade: a revolução da administração. Rio de Janeiro: Marques Saraiva. Fernandes, A. A., \& Teixeira, D. S. (2004). Indústria de Software: implantação e gestão de operações. São Paulo: Atlas.

Florac, W. A. (1992). Software Quality Measurement: A Framework for Counting Problems and Defects. Technical Report. Software Engineering Institute. Carnegie Mellon University.

Fonseca, P. C. (2010). Modelo para controle estatístico de processos de desenvolvimento de software. Dissertação (Mestrado em Ciência da Computação) - Universidade Federal de Minas Gerais. Belo Horizonte, $144 \mathrm{f}$.

Galin, D. (2018). Software quality: concepts and practice. 1 ed.: Wiley-IEEE Computer Society. 
Garvin, D. A. (1987). Competing on the Eight Dimensions of Quality. Harvard Business Review, 65(6). 101-109.

Garvin, D. A. (2002). Gerenciando a Qualidade: a Visão Estratégica e Competitiva. Rio de janeiro: Editora Qualitymark.

Ghanbari, H., Vartiainen, T., \& Siponen, M. (2018). Omission of quality software development practices: a systematic literature review. ACM computing surveys, 51(2), 1-27. https://doi.org/10.1145/3177746

Juran, J. M., \& Gryna, F. M. (1991). Controle da Qualidade Handbook - Conceitos Políticas e Filosofia da Qualidade. Volume 1. São Paulo: Makron Books do Brasil.

Kan, S. H. (2002). Metrics and Models in Software Quality Engineering. Boston: Addison Wesley. Koscianski, A., \& Soares, M. S. (2007). Qualidade de Software. Novatec.

Lopes, T., Costa, M. T., Fernández-Llimós, F., Amante, M. J., \& Lopes, P. F. (2012). A Bibliometria e a Avaliação da Produção Científica: indicadores e ferramentas. BAD - Associação Portuguesa de Bibliotecários, Arquivistas e documentalistas.

Mello, C. H. P. (2012). Gestão da Qualidade. São Paulo: Editora Pearson.

Middleton, P. (2001). Lean software development: two case studies. Software Quality Journal, 9, 241252. https://doi.org/10.1023/A:1013754402981

Miguel, P. A. C. (2001). Qualidade: Enfoques e Ferramentas. São Paulo: Artliber Editora.

Pereira, I. M. (2014). Desenvolvendo software inovador em universidades públicas: Adaptando processos ágeis para a realidade de laboratórios de pesquisa e desenvolvimento. Disponível em:

https://www.repositorio.ufop.br/bitstream/123456789/3512/1/DISSERTA\%c3\%87\%c3\%830_ DesenvovendoSoftwarelnovador.pdf

Perucci, C. C., \& Campos, F. C. (2016). Técnicas de qualidade aplicadas em software: um estudo bibliométrico. Revista de Ciência \& Tecnologia, 19(38), 5-15. http://dx.doi.org/10.15600/22381252/rct.v19n38p5-15

Pressman, R. S. (2011). Engenharia de Software: Uma Abordagem Profissional. 6ạ. Ed. Porto Alegre: McGrawHill.

Pirsig, R. M. (1974). Zen and the Art of Motorcycle Maintenance. New York: Bantam Books.

Scalvenzi, L., \& Miguel, P. A. C. (2016). QFD aplicado ao desenvolvimento de software: priorização de requisitos do cliente em uma matriz de funções. Exacta - EP São Paulo, 14(4), 677-692. https://doi.org/10.5585/exactaep.v14n4.6591

Silva, E. L. L., \& Milfont, F. G. A. (2019). Correlação e proposta de adaptação do MASP às etapas do framework Scrum. Revista de Engenharia e Pesquisa Aplicada, v. 4, n. 4, p. 73-81. https://doi.org/10.25286/repa.v4i4.1234

Sommerville, I. (2011). Engenharia de Software. 9a . Ed. São Paulo: Pearson. 
Sonda, F. A., Ribeiro, J. L. D., \& Echeveste, M. E. (2000). Aplicação do QFD no desenvolvimento de software: um estudo de caso. Produção, 10(1), 51-75. https://doi.org/10.1590/S010365132000000100004

Tarí, J. J., \& Sabater, V. Quality Tolls and techniques: Are they necessary for quality management? International Journal of Production Economics, 92(3), 267-280. https://doi.org/10.1016/j.ijpe.2003.10.018

Thomson Reuters. Using Bibliometrics: A guide to evaluating research performance withcitation data. Disponível em: <http://thomsonreuters.com/products/ip-science/04_030/using-bibliometricsa-guide-to-evaluat-in g-r ese arc h-p erforman ce- wit h-c itation-data.pdf $>$. Acesso em agosto 2019.

Vasconcelos, A. M., Rouiller, A. C., Machado, C. A. F., \& de Medeiros, T. M. M. (2006). Introdução à Engenharia de Software e à Qualidade de Software. Lavras: UFLA/FAEPE.

Velthuis M. G. P., Muñoz, C. C., \& de La Rubia, M. A. M (2010). Calidad del producto y proceso software. RA-MA S.A. Editorial y Publicaciones.

Yue, C. (2019). A projection-based approach to software quality evaluation from the users' perspectives. International Journal fo Machine and Learning and Cybernetics, 10, 2341-2353. https://doi.org/10.1007/s13042-018-0873-y

Zupic, I., \& Čater, T. (2015). Bibliometric Methods in Management and Organization. Organizational Research Methods, 18(3), 429-472. https://doi.org/10.1177/1094428114562629 